\title{
EL IMPACTO DEL DERECHO DE LA UE EN LA REGULACIÓN ESPAÑ̃LA DE LA INTERVENCIÓN ADMINISTRATIVA EN LA ACTIVIDAD ECONÓMICA
}

\author{
Luis Cosculluela Montaner \\ Catedrático de Derecho Administrativo
}

\begin{abstract}
RESUMEN
El ordenamiento jurídico español antes de nuestra adhesión a las Comunidades Europeas se basaba con relación a las actividades económicas privadas en un sistema de control a priori instrumentado a través de la técnica de la autorización o licencia. La adhesión de España a las Comunidades Europeas supuso en esta materia una leve corrección del derecho español. Sin embargo, la aprobación de la Directiva de servicios ha supuesto un cambio de paradigma del sistema administrativo europeo, que en España se ha consolidado por la transposición de la Directiva a través fundamentalmente de cuatro leyes: la Ley 17/2009 (Ley Paraguas), la Ley 25/2009 (Ley Ómnibus), la Ley 2/2011, de Economía sostenible, y la Ley 20/20/2013, de Garantía de la Unidad de Mercado. Sin embargo, este modelo que preconiza una eliminación de controles a priori, salvo excepciones, para postular declaraciones responsables o comunicaciones previas, ha presentado algunas reticencias a nivel del legislador autonómico, y de las corporaciones locales en el plano de gestión.
\end{abstract}

Palabras clave: Directiva de Servicios; autorización; declaración responsable; comunicación previa; silencio administrativo positivo; inspección; control judicial.

\begin{abstract}
Spain's legal system regarding regulated economic activities and services was based before the EU accession on prior control by the competent authorities. The operator had to obtain an explicit positive decision from the administration before starting business, an authorization or a licence. This scenario changed due to the implementation of the EU Directive on Servicesin the internal market, which was im 'lemented in our country mainly through four different laws: 17/2009 (called «umbrella law»), 25/2009 (called «omnibus law») 2/2011 of Sustainable Economy and 20/2013 of Market Unity. Authorization regime was changed in many cases for the least burdensome system of beginning the corresponding activity after the presentation of a responsible statement or prior communication. However, it has caused reticence amongst the regional legislators and local authorities concerning terms of management.
\end{abstract}

Key words: EU' Directive on Services in the internal market; authorisation; responsible statement; prior communication; affirmative administrative silence /implied positive response from the competent authority; inspection; judicial review. 


\section{SUMARIO}

I. LAS INFLUENCIAS RECÍPROCAS DEL DERECHO DE LA UE Y LOS DERECHOS NACIONALES.II. El ordenamiento español antes de 1984. - III. El Derecho de la UNión EuROPEA ANTES DE 2006 EN MATERIA DE INTERVENCIÓN ADMINISTRATIVA EN LA ACTIVIDAD económica.-IV. La transposición de la Directiva de Servicios por el Estado ESPaÑOL.-V. La transposición de la Directiva de Servicios Por las comunidades AUTÓNOMAS Y ENTIDADES LOCALES.-VI. El CONTROL JUDICIAL EN ESPAÑa DE LA TRANSposición de la Directiva de SERVicios.

I. LAS INFLUENCIAS RECÍPROCAS DEL DERECHO DE LA UE Y LOS DERECHOS NACIONALES

La influencia del derecho de la UE sobre los derechos nacionales está clara, pues se deduce de los propios Tratados constitutivos de la UE que han previsto la utilización del derecho para la consagración de la política de formación de la Unión Europea. La recíproca también, así se reconoce por toda la doctrina, pero con un importante matiz, cuando se confirma esta influencia de los derechos nacionales sobre el derecho de la UE, la doctrina dominante en los demás países europeos sólo se refiere al derecho francés, al alemán, al del Reino Unido, y sobre instituciones concretas al derecho de los países nórdicos, en particular el sueco. Existe una nula referencia al derecho español, y tampoco al italiano, pese a que este último dio nombre al tipo de norma europea fundamental en la regulación de la materia económica general: la Directiva.

\section{El ORDENAMiento ESPAÑOL ANTES DE 1984}

Los principios en que se basaba la regulación del derecho español de la intervención en la actividad económica antes de nuestro ingreso en la Comunidad Económica Europea en 1984 era sustancialmente diversa a la actual, aunque debe reconocerse que el gran cambio no se produjo por la incorporación del acervo jurídico comunitario existente en el momento del ingreso, sino en una etapa posterior y reciente, como resultado de la aprobación de la Directiva Bockestein, relativa a los servicios en el mercado interior en el año 2006.

Nuestro derecho administrativo preconstitucional había supuesto un notable distanciamiento con el régimen político en el que surgió. Centrándonos en la regulación de la intervención administrativa de la actividad económica, nuestro derecho administrativo había evoluciona- 
do también desde que se abandonó la política de economía autárquica hacia una economía de mercado en un proceso que se desarrolla en la segunda mitad de los años cincuenta, en la que el control político-administrativo debía respetar la libre iniciativa. Pero nuestro derecho siguió fiel a la declaración de servicio público de las actividades centrales de la economía, consagrando incluso el régimen de monopolio en muchos de ellos. Aunque cuando se establece la política de planificación indicativa de nuestra economía, llegó a consagrarse el principio de subsidiaridad en la ley que aprobó el III Plan de Desarrollo, como orientador de la política de creación de empresas públicas.

Naturalmente, tras nuestra entrada en la Unión Europea los sectores económicos en los que existían empresas en régimen de monopolio perdieron primero su régimen de monopolio y, más tarde, la mayoría de esos sectores perdieron incluso su carácter de servicio público, para pasar en la mayoría de los casos a convertirse en actividades de interés general, o actividades reguladas. Tema que no es objeto de este trabajo.

El segundo gran sector de la actividad económica estaba presidido por el principio de libre iniciativa, que incluso, como se ha dicho, se llegó a reforzar con la invocación del principio de subsidiaridad; pero este sector de actividades económicas privadas estaba dominado por la amplia gama de técnicas de injerencia pública en dichas actividades económicas privadas. Por una parte, por una amplia política de subvenciones que interferían las reglas de la competitividad (tema que no es objeto de este estudio), y, por otra, por una nutrida gama de controles públicos.

En este punto de los controles administrativos sobre la actividad económica privada, habría que diferenciar dos ámbitos, el de las actividades económicas de competencia estatal y el de las competencias locales. En ambos ámbitos la técnica estrella era la autorización, que suponía un control a priori del desarrollo de la actividad autorizada. Para la primacía de este sistema de control implantando la técnica autorizatoria pesaban dos razones fundamentales: la primera, que nuestra burocracia estaba anclada en el trabajo de "despacho» o de "oficina», y no en el trabajo de "campo", con lo que la actividad de inspección estaba en nuestra Administración poco desarrollada, se prefería hacer descansar todo el control sobre el examen a priori de la documentación aportada por el propio particular interesado y no en una labor inspectora in situ.

La segunda razón es que nuestro sistema jurídico, al igual que el de otros países continentales europeos, no había desarrollado (y sigue sin hacerlo), un buen funcionamiento de la acción de responsabilidad extracontractual, que redunde en un amplio sistema de seguros de la actividad emprendida, y, por el contrario, nuestra cultura era (y es) propicia 
a hacer recaer finalmente la responsabilidad por los daños de cualquier actividad, aunque sea privada, en los poderes públicos encargados de controlarla, buscando la garantía de la solvencia económica de éstos, frente a la incierta solvencia del particular responsable directo del daño causado, por lo que se produce la reacción administrativa de aumentar el control $a$ priori de las actividades privadas. Y ello pese a la categórica disposición del art. 12 de nuestro Reglamento de Servicios de las Corporaciones Locales de 1955 que preveía que los titulares de autorizaciones no pueden invocarlas para excluir o reducir su responsabilidad civil o penal en la que hubieran incurrido, por lo que ante ese desplazamiento hacia la Administración pública de la responsabilidad subsidiaria en supuestos de conductas privadas se producía la reacción de los poderes públicos de aumentar el control de dichas actividades privadas.

En el ámbito de lo local, a esas dos razones se añadía otra razón no menos importante: la técnica autorizadora era una de las fuentes de financiación de las entidades locales más relevante, a través de las tasas que se anudaban a la tramitación de las autorizaciones y licencias.

III. El DeRecho de la Unión Europea antes de 2006 en materia de INTERVENCIÓN ADMINISTRATIVA EN LA ACTIVIDAD ECONÓMICA

A) El cuadro descrito de nuestra regulación de la actividad económica privada antes de nuestra entrada en la Comunidad Económica Europea y la Comunidad de la Energía Atómica por el Tratado de Adhesión de 12 de junio de 1985 no se correspondía con el derecho de la UE, por lo que España se vio obligada a una urgente adaptación de nuestro derecho en la materia que comentamos al acervo comunitario. Las discrepancias entre ambos ordenamientos derivaban, en primer lugar, de que el derecho de la UE se basa en un modelo económico que su ordenamiento garantiza y pretende instalar en todos los países de la UE: el modelo de economía de mercado, y los principios de libre iniciativa y de libre competencia. Un modelo próximo al liberalismo económico, aunque matizado por el denominado Estado de bienestar, por lo que el modelo europeo, siguiendo la doctrina alemana, se denomina de economía social de mercado. Dicho modelo de la UE se ha impuesto a todos los Estados miembros, fundamentalmente a través de la técnica de las Directivas y ha supuesto terminar con los monopolios, excluir las ayudas públicas que distorsionen el principio de libre competencia y en general propiciar la implantación de un mercado común no discriminatorio entre los Estados miembros, que permita la 
efectividad del principio de la libre circulación de personas, servicios y capitales.

En definitiva, el modelo de la UE en lo económico que se deriva de los Tratados europeos es el de un capitalismo controlado por el Poder público y compatible con el Estado de bienestar, para lo cual sienta el principio de que las actividades económicas privadas se rigen por el principio de libre incoativa y el sometimiento al principio de competencia.

B) Este modelo se modifica en 1992, reforzando las medidas para hacerlo efectivo, con la aprobación del Tratado de Maastricht con el que se da un gran impulso a la unión económica y monetaria de la Unión Europea, que desembocará en la creación del euro como moneda única y la realización a través de Directivas de una política de crecimiento sostenible y no inflacionista, que debe respetar el medio ambiente, un alto nivel de empleo y de elevación y calidad del nivel de vida.

Con la aprobación del Tratado de Amsterdam (1997) se crea un nuevo marco jurídico que permite que se desarrolle una amplia labor del Tribunal de Justicia de la Unión Europea, que supone la consagración pretoriana en términos de aplicación plena de los principios de subsidiaridad y proporcionalidad en la acción administrativa, y de seguridad jurídica y confianza legítima en la actividad normativa, que consolida un entramado jurídico que consagra un status libertatis del ciudadano de la Unión. En este sentido se ha destacado (T. R. Fernández) que la Sentencia de 22 de enero de 2002, caso Canal Satélite Digital, S.L., sentó los criterios para que un régimen de autorización administrativa previa deba estar justificado. A este fuerte impulso jurisprudencial se unirá el Tratado de Roma de 2004, que aunque fracasó en su finalidad de establecer una Constitución europea supuso un meritorio intento de clarificación del derecho de la UE, que abonará un proceso que culminará con la aprobación en el Tratado de Lisboa de dos Tratados: el Tratado de la Unión Europea (TUE) y el Tratado de Funcionamiento de la Unión Europea (TFUE).

En el marco del Tratado de Roma se aprueba la Directiva de Servicios (Directiva Bolkestein) 2006/123/CE, del Parlamento Europeo y del Consejo, de 12 de diciembre de 2006, relativa a los servicios en el mercado interior. Directiva considerada como decisiva en el que ha sido concebido como un cambio de paradigma en el derecho administrativo de los Estados de la UE, y que por lo que a este estudio importa ha supuesto un cambio fundamental en el régimen de intervención de la Administración pública en las actividades económicas privadas. 
El objetivo de la Directiva de Servicios es imponer en el seno de la UE un régimen de libertad de la iniciativa privada en las actividades económicas (no excluidas por la Directiva) como regla general, y condicionando que pueda establecerse por los Estados miembros un sistema de control que, obediente al principio de menor onerosidad, excluye como técnica preferente los controles ex ante. El régimen de autorización, que comporta un control a priori, debe someterse a las condiciones que establece el art. 9 de la Directiva, y entre ellas a que, para establecerla, se justifique su necesidad por una razón de interés general. Se trata de un concepto jurídico indeterminado, que no obstante tiene en el art. 4.8 de la propia Directiva algunos parámetros para su correcta aplicación: la propia Directiva establece que se trata de una razón reconocida como tal por la jurisprudencia del Tribunal de Justicia de la Comunidad Europea, e incluye en todo caso:

[...] el orden público, la seguridad pública, la protección civil, la salud pública, la preservación del equilibrio financiero del régimen de la Seguridad Social, la protección de los consumidores de los destinatarios de servicios y de los trabajadores, las exigencias de la buena fe en las transacciones comerciales, la lucha contra el fraude, la protección del medio ambiente y del entorno urbano, la sanidad animal, la propiedad intelectual e industrial, la conservación del patrimonio histórico y artístico nacional y los objetivos de la política social y cultural.

Los supuestos de excepción que permiten imponer el régimen de autorización son, por tanto, numerosos, y tienen un valor ejemplificativo, que no supone definir una lista cerrada, pero que obliga caso de establecer un régimen de autorización a justificar su necesidad en cada supuesto. Sin embargo, la Directiva no se aplica a todos los servicios, sino a las actividades económicas de naturaleza privada, por lo que no están incluidos los servicios de interés económico general. También se excluye de la aplicación de esta Directiva a los servicios financieros (banca, crédito, seguros, fondos de inversión), los de comunicaciones electrónicas, los audiovisuales y los de transporte, así como los servicios sociales y los sanitarios. La Directiva viene a regular los servicios de carácter económico puro, es decir, los que se realizan por una contrapartida económica.

Con todo, no faltan opiniones que sostienen que el legislador, europeo se ha excedido en sus competencias (Cuadra-Salcedo), y que la ideología liberal ha terminado por pesar más en los órganos de gobierno de la UE que el respeto a los Derechos de los Estados miembros. Debe 
tenerse en cuenta, además, que la Directiva considera que el logro de sus objetivos no se fía sólo a la trasposición dentro del plazo establecido por la propia Directiva para su trasposición a los Ordenamientos de los Estados miembros, sino que lo considera como un proceso que debe ir consiguiendo todos sus objetivos a lo largo de un tiempo más dilatado, en el que el espíritu de la Directiva vaya calando en un verdadero cambio de mentalidad de las autoridades administrativas.

La regulación que vino a establecer la Directiva obedece a los siguientes principios:

A) Supresión, como regla general, de todas las autorizaciones que impliquen un control a priori de la actividad privada a realizar, admitiendo tan solo aquellos supuestos en que no resulte eficaz otro tipo de control, por los riesgos y peligros que se puedan derivar de la supresión de dicho control a priori.

B) Imponer en los casos en que se pueda establecer un régimen de autorización, que se justifique su imperiosa necesidad por razones de interés general y con respeto a los principios de no discriminación y de proporcionalidad. La Directiva remite las razones de imperiosa de interés general a las que sean reconocida como tales por el Tribunal de Justicia y enumera una serie de ellas que considera incluidas en este supuesto, en un listado que tiene carácter ejemplificativo (art. 4.8).

C) Prevé, con carácter general, que en los procedimientos en que resulte justificado el establecimiento de una autorización, el silencio administrativo, en su caso, debe tener carácter positivo. Sólo por razón imperiosa de interés general, incluidos los legítimos intereses de terceros, se podrá regular un sistema de silencio negativo.

D) Eliminar los requisitos formales que supongan una carga para acceder a las actividades reguladas por la Directiva, como son los supuestos retrasos, costes, duplicación de operaciones, formalidades burocráticas en la presentación de documentos, plazos indeterminados o excesivamente largos para otorgar la autorización, autorizaciones con vigencia muy limitada, gastos y sanciones desproporcionados, o poder arbitrario de autoridad competente para otorgar la autorización.

E) Facilitar toda la gestión administrativa mediante la creación de ventanillas únicas, que garanticen a los prestadores de servicios poder desarrollar a través de ellas todos los procedimientos y trámites precisos para acceder a las actividades sujetas a la aplica- 
ción de la Directiva; y establecer una información amplia y de fácil acceso, y un sistema de gestión electrónico.

F) La Directiva contiene también una amplia regulación de ejercicio profesional, que buscaba su liberalización en aras de una más amplia competencia entre los profesionales.

\section{La transposición de la Directiva de Servicios por el Estado español}

Dado el carácter de Estado políticamente descentralizado, la transposición a nuestro ordenamiento jurídico de las Directivas de la UE debe tener en cuenta las competencias legislativas tanto del Estado, como las de las comunidades autónomas. Sin embargo, el responsable de dicha transposición ante la UE es el Estado por lo que no han faltado voces que han postulado una asunción estatal de las competencias de transposición de la Directiva de Servicios, tomando como fundamento los títulos competenciales previstos en el art. $149 \mathrm{CE}$ los números $1.1^{\mathrm{a}}$ (en relación con el derecho a la libre iniciativa que reconoce el art. 128.2; $13^{\mathrm{a}}$, bases y coordinación de la actividad económica y $18^{\mathrm{a}}$, bases del régimen jurídico de las Administraciones públicas y del procedimiento administrativo común.

Sin embargo, este efecto de la transposición de Directivas europeas supondría una recentralización de competencias en favor del Estado que el TC ha considerado inconstitucional. La responsabilidad estatal en orden a la citada transposición del derecho de la UE se ha traducido en que el Estado se ha reservado legislativamente el derecho a repercutir el importe de las sanciones económicas que pudiera acarrearle el incumplimiento de dicha transposición en la financiación que deba transferir el Estado a esa Administración que motivó la sanción.

A) A nivel estatal la transposición de la Directiva de Servicios se ha llevado a cabo por dos leyes estatales fundamentales, la Ley 17/2009, de libre acceso a las actividades de servicio y su ejercicio, conocida como Ley Paraguas, y la Ley estatal 25/2008, de 22 de diciembre, de modificación de diversas leyes para su adaptación a la ley sobre el libre acceso a las actividades de servicio y subejercicio, conocida como Ley Ómnibus. A estas dos leyes habría que añadir la Ley 2/2011, de Economía Sostenible, y la Ley 20/2013, de Garantía de la Unidad de Mercado, que consolidaron la incorporación a nuestro ordenamiento del espíritu de la Directiva de Servicios. La Ley Paraguas ha sido objeto de aguda crítica por el Informe del Consejo de Estado por cuanto es una ley que en gran 
parte de su contenido se limita a establecer disposiciones meramente descriptivas y otras disposiciones carecen de efectos inmediatos, por lo que ha considerado que es una disposición con escasa virtualidad normativa y que no despliega plenamente sus efectos.

B) La Ley Paraguas supuso la modificación de 50 leyes y 115 reales decretos, y la Ley Ómnibus modificó 38 leyes estatales. Por su parte, las comunidades autónomas han debido modificar 193 leyes autonómicas, 487 Decretos y 113 órdenes. A lo que debe añadirse las modificaciones que han debido adoptar las corporaciones locales en sus correspondientes reglamentos y ordenanzas, de las que carezco del dato exacto. Todo lo cual da idea de la gran transformación sufrida por nuestro ordenamiento jurídico como consecuencia de la transposición de la repetida Directiva.

Por su parte, la Ley de 2/2011, de Economía Sostenible. Al margen de su incidencia en el mercado financiero y de seguros, energético, de transportes y de gestión de infraestructuras y de la vivienda, ha supuesto una revisión de procedimientos administrativos de intervención administrativa en la actividad privada que viene a continuar los ya previsto por las Leyes Paraguas y Ómnibus, en particular, por su ampliación del ámbito de aplicación del silencio administrativo positivo, y ha modificado directamente en sus Disposiciones Transitorias 40 leyes, al margen de otras de carácter estrictamente fiscal. La Ley de Economía Sostenible aprobó también en su Anexo I la modificación de más de 100 procedimientos administrativos modificando el sentido del silencio administrativo que era negativo y convirtiéndolo en positivo.

El modelo actual del derecho español en la regulación de la intervención administrativa de la actividad económica, de acuerdo con lo estableado en la Directiva europea de servicios, puede establecerse que responde a los siguientes principios:

1) El principio general para el ejercicio de las actividades privadas de carácter económico es el de libertad de establecimiento en todo el territorio nacional, y las técnicas de control público de dicha actividad que, en su caso, se establezcan son, como regla general, controles a posteriori.

2) El régimen de autorización o de cualquier control a priori del acceso o ejercicio de la actividad económica privada es la excepción, y para imponerlo debe respetar los principios de no discriminación y proporcionalidad, y solo puede establecerse cuando esté justificado por razones de interés general: orden público, seguridad pública, protección civil, salud pública, preservación del 
equilibrio financiero del régimen de la Seguridad Social, protección de los derechos, la seguridad y la salud de los consumidores y de los trabajadores, las exigencias de la buena fe, la lucha contra el fraude, protección del medio ambiente y del entorno urbano, la sanidad animal, la propiedad intelectual e industrial, la conservación del patrimonio artístico nacional y los objetivos de la política social y cultural. Listado que, a diferencia del establecido en la Directiva, con el que no coincide exactamente, es cerrado y no ejemplificativo.

3) Como consecuencia, la técnica de control dominante del acceso o ejercicio de actividades económicas es, en su caso, el establecimiento de la obligatoriedad de la declaración responsable o la comunicación previa del comienzo del ejercicio de la actividad. Técnica, esta última, que ya estaba recogida en el Reglamento de Servicios de las Corporaciones Locales de 1955 para la simple comunicación de las obras menores, y se ha plasmado en el art. 39 bis de la Ley 30/1992 del Procedimiento Administrativo Común y en el art. 69 de la nueva Ley del Procedimiento Administrativo Común (en adelante, LPC), que entrará en vigor el próximo octubre.

4) Esta regla supone que el control de la actividad privada por la Administración se hace descansar sobre la labor inspectora, y debe ser, por tanto, un control a posteriori. Aunque debe advertirse que en el propio art. 69 de la LPC prevé para la declaración responsable que la Administración podrá requerir en cualquier momento que se aporte la documentación que acredite el cumplimiento de los requisitos establecidos en la norma y que el interesado manifiesta cumplir.

Las autorizaciones, cuando la norma que la establece justifique su exigencia, tienen carácter reglado, y el silencio administrativo, de producirse, es positivo. El silencio administrativo negativo debe establecerse únicamente por una norma de derecho de la UE o norma con rango de ley y justificarse por razones de imperiosa necesidad de interés general (art. 24.1 in fine LPC). Y, con carácter general, la autorización se otorga por tiempo indefinido, y no cabe una limitación del número de autorizaciones, salvo que exista escasez de recursos naturales o inequívocos impedimentos técnicos.

Sin embargo, la Disposición Adicional $4^{a}$ de la Ley Ómnibus supuso una interpretación muy particular respecto de la transposición al derecho español de la Directiva de Servicios en materia del silencio administrativo, al establecer que «a los efectos previstos en el primer párrafo del art. 
43.1 de la Ley 30/1992..., de acuerdo con la redacción dada por la presente ley, se entenderá que concurren razones imperiosas de interés general en aquellos procedimientos que, habiendo regulado con anterioridad a la entrada en vigor de esta ley por normas con rango de ley o de derecho comunitario, prevean efectos desestimatorios a la falta de notificación de la resolución expresa del procedimiento en el plazo previsto». Lo que suponía reconocer como vigente un valor desestimatorio a supuestos regulados por el legislador en tal sentido con anterioridad a la transposición. Supuestos que se establecieron en el marco de un modelo propicio a establecer efectos negativos al silencio administrativo, que no se compadece con lo establecido tras la transposición de la Directiva de Servicios. De ahí que la Ley de Economía Sostenible completase la adaptación de la Directiva de Servicios, imponiendo que se remitiera a las Cortes un proyecto de ley de modificación del sentido del silencio administrativo en los procedimientos que a los que no se consideren cubiertos por razones de interés general (art. 40), ley que, además, modificó directamente la Ley básica 30/1992, del Procedimiento Administrativo Común, añadiendo los artículos 84 bis y 84 quater, y una amplia relación de leyes reguladoras de importantes sectores de la actividad económica.

En definitiva, el modelo español de intervención administrativa sobre la iniciativa económica privada se ha modificado sustancialmente en el plano normativo, lo que ha supuesto, siguiendo los principios de la Directiva de Servicios, una profunda eliminación de la técnica autorizadora, y, solo en el caso de considerarlo justificado, mantener la autorización con aplicación, en su caso, de la técnica del silencio administrativo positivo en el procedimiento de su otorgamiento. Aunque, en la mayoría de supuestos, el legislador español ha preferido sustituir la técnica autorizadora, siguiendo el principio de optar por las técnicas de menor onerosidad, por otras técnicas que posibiliten, en su caso, un control ex post dando prioridad a las técnicas de declaración responsable o comunicación previa.

En otros ordenamientos, como el italiano, la transposición de la Directiva de Servicios se hace descansar sobre la generalización de la técnica de la Declaración de inicio de actividad (DIA), después sustituida por la Comunicación certificada de inicio de a actividad (SCIA) en el año 2010. Las potestades de control por la Administración ex post se condicionan doblemente por el establecimiento de un plazo de treinta días para ejercerlas y porque solo pueden ejercerse ante un peligro actual de un daño grave e irreparable que se produzca en relación con determinadas materias. Por el contrario, en el derecho español, el art. 24.2 de la LPC Común considera que el silencio administrativo positivo tiene 
a todos los efectos la consideración de acto administrativo finalizador del procedimiento y, por tanto, si se trata de actos favorables como es el supuesto de ejercicio de actividades económicas por los particulares, sólo cabe, en su caso, la revisión de oficio del acto producido por silencio positivo, en los casos de nulidad de pleno derecho.

Por otra parte, el modelo español ha sido un ferviente partidario de la apuesta que la Directiva de Servicios hace por la implantación de la administración electrónica. La Ley 11/2007, de acceso electrónico de los ciudadanos a los servicios públicos, había constituido un primer paso para el establecimiento de un acceso electrónico de los ciudadanos en sus relaciones con las Administraciones públicas, y la Ley Ómnibus, en sus arts. 18 y 19, había regulado la obligación de las Administraciones Públicas de establecer el sistema de ventanilla única, que garantizará el acceso electrónico de los ciudadanos y la interoperatibilidad de los destinos sistemas. Continuando el proceso, estos sistemas de comunicación electrónica la Ley 39/2015 (LPC), cuya una entrada en vigor se prevé para el plazo de un año desde su publicación (es decir, para el 2 octubre de 2016,), establece el plazo de dos años en el caso de los registro electrónicos, punto de acceso general electrónico de la Administración y archivo único electrónico.

A nivel de gestión administrativa, la histórica reticencia de nuestra burocracia hacia una labor de inspección in situ se ha visto favorecida por las innovaciones tecnológicas, en concreto por la informática que permite que en la actualidad las Administraciones públicas dispongan de amplias bases de datos, y el cruce de las mismas permite una labor inspectora más fácil, en la que lo esencial es disponer de información parara detectar mediante ese cruce de datos las posibles infracciones que puedan cometerse. Todo ello no es óbice para que consideremos que la burocracia española debe volcarse más en la formación de cuerpos de inspección in situ de las actividades privadas, y que consideremos que la regulación de la función inspectora no tiene una regulación básica suficiente.

V. La transposición de la Directiva de Servicios por las comunidades AUTÓNOMAS Y ENTIDADES LOCALES

En el Estado autonómico español, la descentralización política supone que las comunidades autónomas también tienen competencia legislativa para la transposición de las Directivas europeas en el marco de sus competencias. Solución que ya estaba apuntada en la propia Directiva 
en la que se afirma que las disposiciones referentes a los regímenes de autorización y al ámbito territorial de una autorización no deben interferir en el reparto de competencias regionales o locales en los Estados miembros, incluidos los gobiernos autónomos y locales (considerando 60). Así se preveía también en el Informe sobre la transposición de la Directiva de Servicios de 2010 que las comunidades autónomas debían modificar 193 leyes, 487 decretos y 113 órdenes. Y ésta es, por otra parte, la solución impuesta por la doctrina de nuestro TC, con carácter general en cuanto afecte a la transposición del derecho de la UE a nuestro ordenamiento.

En términos generales, y respecto a los objetivos de facilitar una liberalización de controles administrativos respecto a las actividades económicas privadas, puede decirse que en este nivel autonómico se ha cumplido con lo dispuesto en la citada Directiva, no sin algunas reticencias graves. El problema está en que la legislación autonómica, aprovechando los denominados títulos cruzados de competencias, ha aprobado, en ocasiones, una legislación contraria a lo establecido en dicha Directiva. En particular eso ha ocurrido invocando como títulos competenciales la protección del medio ambiente o el urbanismo, que en sí mismos pueden considerarse como legitimadores para el establecimiento de la técnica autorizatoria (art. 4,8 de la Directiva); pero que se utilizan como coartada para regular restrictivamente o con una finalidad claramente disuasoria para el operador económico actividades en las que la Directiva establece el principio de libre iniciativa.

En este sentido, merece citarse el problema de la regulación de las grandes superficies comerciales. Tema que partía de la regulación establecida por la Ley estatal 7/1996, de Ordenación del Comercio minorista (posteriormente modificada por la Ley 1/2010), que imponía una licencia específica para la instalación de estos centros comerciales, atribuyendo su otorgamiento a las comunidades autónomas. Tras la transposición al derecho español de la Directiva de Servicios, muchas de las comunidades autónomas que tenían aprobada su correspondiente legislación en esta materia la adaptaron acentuando la intervención administrativa por motivos urbanísticos o de protección del medio ambiente, que se tomaban como pretexto de esta regulación para implantar los controles administrativos de actividades económicas privadas. Con todo el Tribunal de Justicia de la UE ha tenido ocasión de pronunciarse sobre la legislación catalana al respecto en su Sentencia de 24 marzo 2011 (Comisión v. España), condenando a España por cuanto las limitaciones establecidas en Cataluña suponen restricciones a la libertad de establecimiento que no están justificadas. 
La Ley de Economía Sostenible (art. 40.2), teniendo en cuenta estas reticencias de la legislación autonómica, impuso que las comunidades autónomas evaluarán en el plazo de un año las razones para mantener el silencio administrativo negativo en autorizaciones reguladas por normas anteriores a la Ley 25/2009. En la misma línea, la Ley de Garantía de la Unidad de Mercado, ha venido también a establecer una nueva regulación del control administrativo sobre las actividades económicas, insistiendo en el respeto al principio de menor onerosidad del medio de control, que en su caso, proceda establecer, y apuntando a la preferencia por el establecimiento en estos casos de la técnica de la declaración responsable y la comunicación del inicio de la actividad.

Las entidades locales, aunque disponen también de competencias normativas, tienen condicionada dicha potestad dado que se ejerce a través de normas con rango reglamentario. Y las leyes reguladoras de las entidades locales son competencia del Estado y de las comunidades autónomas, que son las que han realizado en lo fundamental la transposición de la Directiva de Servicios en lo que afecta directamente a la actividad que es competencia de las corporaciones locales. Así se han modificado, en virtud de lo dispuesto en la Ley Ómnibus, la Ley 7/1985, de 2 de abril, Reguladora de las Bases del Régimen Local, que añadió el apartado 4 al art. 70 bis y modificó el art. 84 . Y la Ley de Economía Sostenible, por su parte, añadió en su art. 41 los arts. 84 bis y 84 ter a la Ley Reguladora de las Bases de Régimen Local. El art. 84 bis establece que con carácter general el ejercicio de las actividades económicas privadas no se someterá a la obtención de licencia u otro medio de control preventivo y limitando su exigencia además de los casos ocupación de dominio público, a actividades que afecten a la protección del medio ambiente, del patrimonio histórico artístico, la seguridad o la salud pública, e insistiendo en la necesidad motivar expresamente la necesidad de la autorización o licencia que se estableciera precisando el interés general concreto que se pretende proteger. Y se ha modificado también el Reglamento de Servicios de las Corporaciones Locales de 1955 por el R.D. 2009/2009, de 23 de diciembre, suprimiendo dos artículos y remitiendo a la legislación básica en materia de régimen local y a la misma Ley 17/2009 otros dos.

Por otra parte, el legislador sectorial ha privado a las corporaciones locales de cualquier control preventivo de obras públicas de infraestructura que son competencia estatal (por ejemplo, puertos, aeropuertos, visas férreas y obras hidráulicas). Aunque el art. 84.3 (que modificó la Ley Ómnibus) establece la obligación de obtener las licencias o autorizacio- 
nes de las entidades locales, advierte que con respecto a lo dispuesto en las correspondientes leyes sectoriales, que, como hemos visto, tienden en muchos casos a eliminar estos controles locales.

La Ley Ómnibus, por otra parte, a nivel de gestión al mundificar la Ley Básica del Régimen Local, añadiendo el art. 70 bis, establecía la obligación de las entidades locales de establecer una ventanilla única por vía electrónica y a distancia para la tramitación relativa a las actividades incluidas en la Ley Paraguas, y la de facilitar toda la información necesaria tanto para el acceso a dichas actividades como para conocer las resoluciones que se adopten.

Con todo, la experiencia de la aplicación de los objetivos de la Directiva Bolckestein por las entidades locales no es apreciado ni como un proceso aceptado con entusiasmo por estas, ni como exitoso en la práctica. Por otra parte, las elecciones locales de 2015 han supuesto que en algunas ciudades la ideología de los órganos de gobierno se haya mostrado muy poco propicia a aceptar en su política de gestión municipal las consecuencias que se deducen del espíritu de la Directiva de Servicios en cuanto a la intervención en el acceso y desarrollo de actividades económicas privadas, que como se ha dicho no sintoniza con la ideología de dichos grupos municipales.

VI. El control Judicial en España de la transposición de la Directiva DE SERVicios

La transposición al derecho español de las Directivas europeas ha seguido la técnica de convertir en básicas las leyes estatales correspondientes, respetando las competencias normativas de las comunidades autónomas, lo que ha permitido el control del TC sobre la legislación que contraviniera lo dispuesto en dichas leyes básicas. El TC no ha tenido ocasión de pronunciarse sobre la legislación estatal en cuanto a la conformidad de la legislación española con la Directiva de Servicios, su cometido no es ese. Pero sí ha tenido ocasión de enfrentarse con este tema al controlar leyes autonómicas que difieren de la normativa europea aunque no basándose en su eventual disconformidad con el derecho de la UE, sino en la discrepancia de la norma autonómica con la legislación básica estatal de transposición del derecho de la UE, lo que determina una violación de la CE.

Así ha ocurrido con el caso de las prohibiciones y limitaciones que se han establecido con relación a las empresas que ejercen el comercio en las grandes superficies, establecidas por leyes de Cataluña, que moti- 
varon que el TC en las SSTC 26/2012 de 26 de marzo, FJ 5, y 193/2013, FJ 3, haya declarado el carácter formal y materialmente básico, ex art. 149.1.13 CE, del art. 11 de la Ley 17/2009, de 23 de noviembre, sobre el libre acceso a las actividades de servicios y su ejercicio, que incorpora a nuestro ordenamiento la Directiva 2006/123/CE, del Parlamento Europeo, y del Consejo, de 12 de diciembre de 2006, relativa a los servicios del mercado interior.

La contumacia del legislador catalán ha dado lugar a tres sentencias del TC: la primera, la 193/2013 que resolvió un recurso de inconstitucionalidad contra el art. 9 del Decreto Ley 1/2009, de 22 de diciembre., de ordenación de los equipamientos comerciales, que implicaba una prohibición de instalación de grandes superficies comerciales en las tramas urbanas consolidadas, y que fue más tarde vuelta a reproducir en la Ley catalana 2/2014, de Medidas fiscales, administrativas, financieras del sector público (Disposición transitoria $8^{\mathrm{a}}$ ), lo que motivó una nueva Sentencia del TC 17/2016, de 14 de abril de 2016, que en su FJ 4 establece que:

[...] el legislador catalán no exterioriza ninguna motivación orientada a justificar que estas mayores restricciones que ahora se imponen coadyuven proporcionalmente al logro de una gestión urbana sostenible; se limita a conectarlas en general con la reactivación económica y en particular con el incremento de la actividad comercial, motivos ambos que por ser de clara índole económica no resultan acordes con los criterios fijados por la normativa básica del Estado.

Igual declaración de inconstitucionalidad sufrió en la Sentencia del TC 26/2012, la legislación balear que siguió la misma regulación catalana en este mismo tema. Y la propia Sentencia citada del TC 17/20 ha declarado la inconstitucionalidad del apartado $10 \mathrm{del}$ art. $47 \mathrm{del} \mathrm{TR}$ de la Ley de urbanismo, añadido por el art. 167 de la Ley catalana 2/2014, que prohibía la fracturación hidráulica en el aprovechamiento de hidrocarburos, recordando (FJ 9) que aunque caben en nuestro ordenamiento las leges repetitae:

La legislación autonómica puede introducirse en el terreno de lo básico, pero sólo por excepción, cuando se limite a repetir las bases si de este modo contribuye a hacer inteligible el régimen autonómico de desarrollo... [pero] en el presente caso, es evidente que el art. 47.10 TRLUC no es una reproducción o reiteración fiel de las bases que pretenda facilitar la comprensión de un desarrollo autonómico por lo que vulnera las competencias constitucionales del Estado. 
La doctrina del Tribunal Constitucional en las sentencias citadas no alude a la Directiva de Servicios, sino a la violación de una ley básica, la Ley 17/2009, de transposición de la Directiva, pero lo que queremos destacar es que la Directiva una vez realzada su transposición es perfectamente controlada por nuestro Tribunal Constitucional, frente a su desconsideración, por el recurso de inconstitucionalidad al invadir las comunidades autónomas las competencias básicas del Estado, invocadas como título competencial para aprobar la ley de transposición. En cualquier caso, el TC controla especialmente el que cuando se utiliza un título cruzado de competencia, por ejemplo el de urbanismo o protección del medio ambiente, si bien tiene declarado en numerosas sentencias que las comunidades autónomas pueden imponer deberes y cagas para el otorgamiento de autorizaciones, permisos y concesiones, con la finalidad de proteger el medio ambiente, se exige siempre que las mismas sean razonables y promocionadas al fin propuesto, como impone la Directiva de Servicios. Pero la argumentación del TC se limita formalmente a imponer el respeto a lo dispuesto principalmente en los artículos 4 y 5 de la Ley Paraguas, especialmente en lo dispuesto en las siguientes letras de este precepto: $c$ (justificación de la necesidad de establecerse un régimen de autorización) y $d$ (respeto a la proporcionalidad y al principio de menor onerosidad de la técnica de control a priori impuesta), pero obviamente con este modus operandi el TC está controlando el respeto a lo dispuesto en los arts. 9 y 10 de la Directiva de Servicios, a través de la normativa básica de transposición de la misma.

Los Tribunales Ordinarios de lo Contencioso Administrativo, en particular los Tribunales Superiores de Justicia, han sido meticulosos en el control de la aplicación de las leyes y Decretos de transposición de la normativa europea tanto de la normativa reglamentaria como de gestión de las Administraciones públicas, pero han sido igualmente muy propicios a la aplicación de lo dispuesto en la Disposición Adicional $4^{\text {a }}$ de la Ley Ómnibus, en lo referido a la consideración del silencio administrativo negativo establecido en la legislación anterior a la transición por normas españolas de la Directiva. El problema se ha suscitado en particular con relación al ordenamiento urbanístico. De acuerdo con esta Disposición Adicional, la jurisprudencia de los Tribunales de lo Contencioso Administrativo ha seguido manteniendo el silencio administrativo negativo en muchas de las materias, especialmente las que afectan al urbanismo y medio ambiente, que son dos supuestos en que se aprecia la razón de interés general por la Directiva de Servicios. Sin embargo, en otras sentencias de los Tribunales Superiores de Justi- 
cia se establece la aplicación del art. 43.1 de la Ley 30/1992, primando sobre otras previsiones.

En cualquier caso hay una resistencia de nuestros Tribunales de Justicia al planteamiento de cuestiones prejudiciales ante el TJUE, de acuerdo con lo dispuesto en el art. 4.8 de la Directiva de Servicios, para enjuiciar supuestos reconocidos como de razón imperiosa de interés general para mantener un régimen concreto de autorización, en casos no previstos expresamente por la Directiva o el carácter desestimatorio del silencio administrativo, que pueda producirse en los procedimientos para otorgar la autorización (art. 13.4). 